\title{
ASIA SCIENCE AND TECHNOLOGY PORTALS
}

\author{
Phonepaseuth Solinthone ${ }^{1,2^{*}}$, Tatiana Rumyantseva $^{1}$, Anachack Phongtraychack $^{1}$ \\ ${ }^{1}$ National Research Tomsk State University. 634050, Tomsk, Russia \\ ${ }^{2}$ Ministry of Science and Technology, Vientiane, Lao PDR
}

\begin{abstract}
The article presents the information about science and technology portals in Asian countries and their role in dissemination of science and technology-related information. The article describes a new Lao Science and Technology Web Portal launched by the Ministry of Science and Technology of Lao PDR in 2017. The authors analyze goals, content, functions, and benefits of the Lao Science and Technology Web portal as well as problems suppressing its further development.
\end{abstract}

\section{Science and Technology Portals in Asian Counties}

The level of science and technology development in Asian countries varies. Several years ago, India, China and the West Asian civilizations were most notable for their contribution to science and technology development. At present, Japan is likely to be the most notable country in Asia in terms of its technological and scientific achievements; it is a world known country for electronics and automobile products. However, in recent years, China and India have also once again become major contributors to science and technology [1].

The Japanese Government launched the Asia Science and Technology Portal (ASTP) through Japan Science and Technology Agency (JSTA). The ASTP is designed to promote international research collaboration and researcher mobility. The portal contains information on researcher profiles, funding, job vacancies and international meetings. The Asia Science and Technology Portal was developed to support searching of S\&T related information in ASEAN +6 countries (Australia, China, India, Japan, New Zealand and ROK), to promote international joint research and research personnel exchange, to enhance human networking related to S\&T, and to provide fresh and practical information in an effective manner [2].

The ASTP project is carried out as an initiative in science and technology diplomacy of Japan; it is planned and proposed by the Cabinet Office and is operated and managed by JSTA. Sixteen participating countries contribute to the ASTP project.

Initially, the government of Japan proposed creation of an "Open Access Database" for promoting personnel exchanges and joint research among the countries of the region at the "Informal ASEAN+3 (China, Japan and Korea) Ministerial Meeting on Science and Technology" held in Malaysia in August 2006.

\footnotetext{
* Corresponding author: phonepaseuth.slt@gmail.com
} 
In addition, the Report on Science and Technology Diplomacy submitted by the Government of Japan in February 2010, elaborates on the creation of a mutual database for the Asia region as the basis for creation of a global human resources network [3].

As a first step for achieving these goals, JSTA created the Asia Science and Technology Portal based on the initiative of the Cabinet Office.

To consolidate an international framework of the 16 countries in East Asia, the Cabinet Office has contacted, through diplomatic channels, each government for their cooperation and support. Further, Japan introduced the concept and mission of ASTP at the second ASEANJapan Cooperation Committee on Science and Technology in Vientiane, Laos (May 20, 2010). Ten ASEAN members include Brunei, Cambodia, Indonesia, Laos, Malaysia, Myanmar, the Philippines, Singapore, Thailand, and Vietnam [4].

The target group of ASTP includes:

1. Young and promising researchers who wish to conduct joint international research.

2. Researchers who wants to initiate a collaborative research in ASEAN+ six countries;

3. Researchers and policy makers wishing to conduct research on science and technology policies in ASEAN+ six countries.

ASTP provides the following information:

- Research Opportunities (Research Funding, R\&D Job Postings).

- Meetings and Events in Asia.

- Articles and Commentaries related to Joint International Research implemented in the East Asian Region.

Links (Research Results, Human Resource Development \& Research Cooperation, User Facilities)

- R\&D Personnel Directories.

- Universities, Public Research Institutes, Academic Societies.

- Life in Foreign Countries (Housing, Education, Visas, etc.).

- Science and Technology Policies and Indicators in Participating Countries [3].

Information can be searched by country, subject area and keyword. RSS feeds are available for daily updates. Users may communicate through posting comments.

Currently, some Asian countries still have a limited access to data in the field of science and technology. Different organizations attempt to develop specialized web-portals and disseminate science and technology related information [5].

\section{Development of the Lao Science and Technology Web Portal}

In 2017, Ministry of Science and Technology of Lao PDR launched the Lao Science and Technology Web Portal. The portal has the following goals:

- open possibilities for international and domestic collaborations in research for young and promising scientists.

- promotion of S\&T cooperation and stability.

- fostering S\&T growth and high level of employment.

- providing resources not only for scientists but also for policy makers (E-book portal).

The portal represents a website that provides a single point of access to applications and information. From a user perspective, a portal is a web site with pages that are organized by tabs or some other form of navigation. Each page contains a nesting of sub-pages, or one or more portlets with individual windows that display different information from static HTML content to complex web services. A page may contain multiple portlets, giving users access to different information and tools in a single place. Users can also add their own pages, adding portlets of their choosing, and changing the Look and Feel of the interface. 
Lao Science and Technology Web Portal is intended to facilitate the transition process from a common to digital education. The portal has three main areas. The first area deals with education. It includes information about science and technology, various tips and recommendations for students and scientists, and e-books. The second domain is designed to introduce to the users' e- markets and supplier directories. This way we hope to integrate ecommerce to ever province in Laos via business-to-business (B2B) or business-to-government (B2G) cooperation. Finally, it gives an opportunity for a province to introduce its products online. The official domain is "stportal.most.gov.la".

The Ministry of Science and Technology is looking for recognition, for ease of operations, for productivity gains and cost savings, or a combination of all of these advantages; the portal will succeed or fail depending on the perceived benefits to the Ministry. Theoretically, every member of the science and technology community in Laos should benefit from the portal. It should make it easier and more efficient for people to carry out their role in the institution.

The ST web portal provides managers with information and support for effective decisionmaking, and provides feedback on daily operations, output, or reports (generated through accumulation of transaction data). The program will help our organization to reform and move towards the next steps necessary for developing Lao S\&T system.

\section{The Goals of the Lao Science and Technology Web portal}

Currently, there is a number of limitations pertaining to how S\&T information is being managed, reported and promoted in Lao PDR. The authors have identified the following key limitations:

1. Limited capacities to analyze S\&T information.

2. S\&T information is not detailed enough to meet the users' needs.

3. Lack of business integration with science, technology and innovation.

4. Lack of skilled staff and human resource capacities engaged in research.

5. Lack of quality data dissemination on a regular basis.

6. Poor financial support for research in science and technology.

7. Limited access to international resources and data.

8. Poor infrastructure, which leads to slow internet connectivity and its malfunctioning in remote places.

9. Absence of Institute for Science and Technology.

Based on the limitations noted above, the following targets have been identified for the Lao Science and Technology Web Portal:

1. Open up possibilities for international and domestic collaboration in research for young and promising scientists.

2. Promotion of S\&T cooperation and stability.

3. Fostering S\&T growth and high levels of employment.

4. Providing resources not only for scientists but also for policy makers (E-book portal).

5. Integration of business (E-Market).

The portal represents a website that provides a single point of access to applications and information. From a user perspective, the portal is a web site with pages that are organized by tabs or some other form of navigation. Each page contains a nesting of sub-pages, or one or more portlets with individual windows that display different information from static HTML content to complex web services. A page can contain multiple portlets, thus giving users access to different types of information and tools in a single place. Users can also customize their view of a portal by adding their own pages, adding portlets of their choice, and changing the Look and Feel of the interface. 
Lao Science and Technology Web Portal is intended to facilitate the transition process from a common to digital education. The portal has three areas of action. The first area deals with education. It includes information about science and technology, various tips and recommendations for students and scientists, and e-books. The second domain is designed to introduce e- markets and supplier directories to the users. This will help to integrate ecommerce to every province in Laos via business-to-business (B2B) or business-togovernment (B2G) cooperation. Finally, it gives an opportunity for a province to introduce its products online.

\section{Content of the Lao Science and Technology Web Portal}

Lao Science and Technology Web Portal contains the following sections:

1. News and Information on science and technology.

- Selecting the journal articles. The selected articles must be related to environmental research published in peer-reviewed open-access high-impact journals. The articles should be recent (published within the past year) and cover a variety of topics such as science and technology, pollution, endangered species conservation, climate change, and others.

- Text adaptation. The articles are then rewritten in the Lao language using common vocabulary, real-world examples and comparisons where appropriate.

- The draft text is then edited and approved by the scientists who published the original research paper. The finalized text is then edited for aesthetics and readability by creating an appealing layout and adding illustrations.

2. E-book portal overview. Science and technology portal contains E-book Supplemental Materials for Lao people. The main idea is to collaborate with schools, universities and institutes form Laos and other countries as well as to collect and create e-books for Lao people, especially in the field of agriculture because about $70 \%$ of Lao people are farmers using low-level technology.

3. E-Market overview. Integration of business and ecommerce with each Lao province. It means that every province can upload their products to the web portal by means of central level-super admin.

\section{Functions of the Lao Science and Technology Web Portal}

The main functions of the Lao Science and Technology Web Portal include the following:

1. Search. Giving the people who visit the web portal the ability to easily find the information that they are looking for is a key component in creating a user-friendly website. Website navigation that is easy to use and understand is essential to userfriendliness, but sometimes website visitors need more than intuitive navigation to find the content that they are seeking. This is where a website search feature can be essential. Information can be searched by a subject area and a keyword.

2. RSS feeds. RSS (Rich Site Summary; originally RDF Site Summary; often called Really Simple Syndication) uses a family of standard web feed formats to publish frequently updated information: blog entries, news headlines, audio, and video. RSS feeds enable publishers to syndicate data automatically. RSS feeds are available for daily updates. RSS Feeds function is shown in Figure 1. 


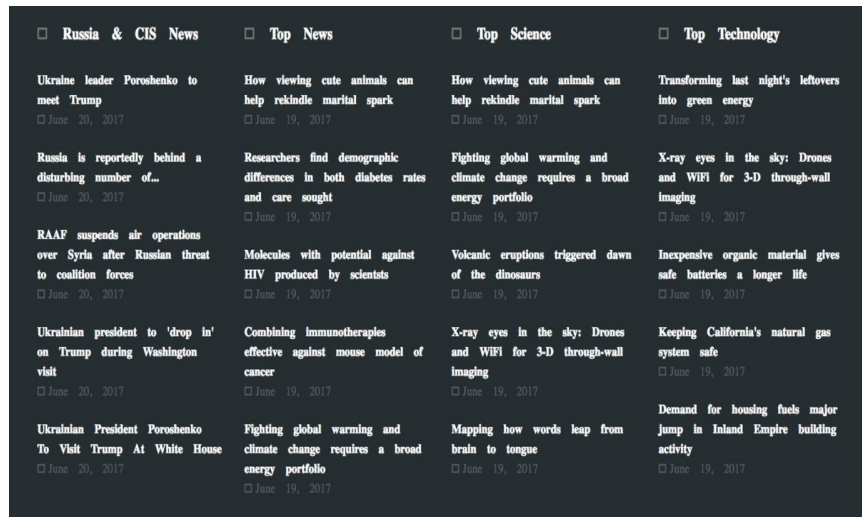

Fig. 1. RSS Feeds function [6].

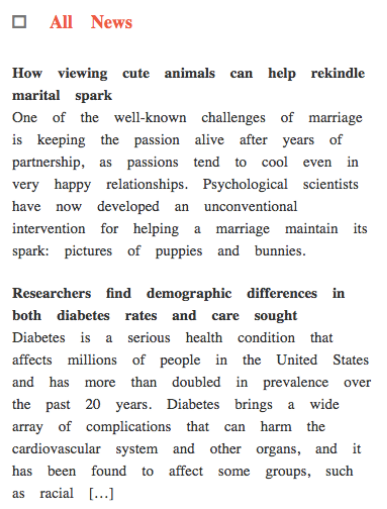

as racial $[\ldots]$

3. Social media. The Social Media Icons Widget lets you add icons for the most popular social networks to sidebar or other widget area. The icons are linked to social media profiles, giving readers access to your latest status updates of the following social networks: Facebook, Twitter, and Gmail. Social media function is shown in Figure 2.

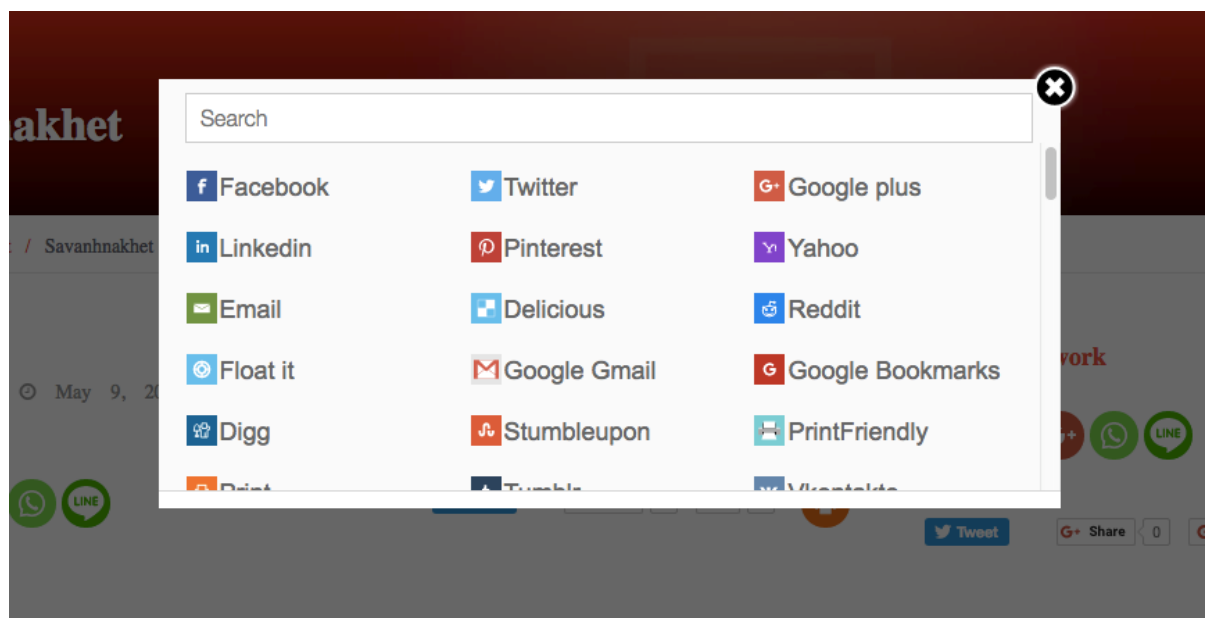

Fig. 2. Social media function [6].

4. E-books. An electronic book (or e-book) is a book publication available in a digital form, consisting of text, images (or both), readable on the flat-panel display of computers or other electronic devices. Although sometimes defined as "an electronic version of a printed book", some e-books exist without a printed equivalent. Education (Universities, Public Research Institutes, and Academic Societies) support books (Research Results, Human Resource Development \& Research Cooperation, User Facilities) for Students and researchers. This E-book project is supported by the Ministry of Science and Technology, Ministry of Education and Sport of Laos, University, Institutes, and international partners. Interface of E-book collection supported by National Research Tomsk State University is shown in Figure 3. 


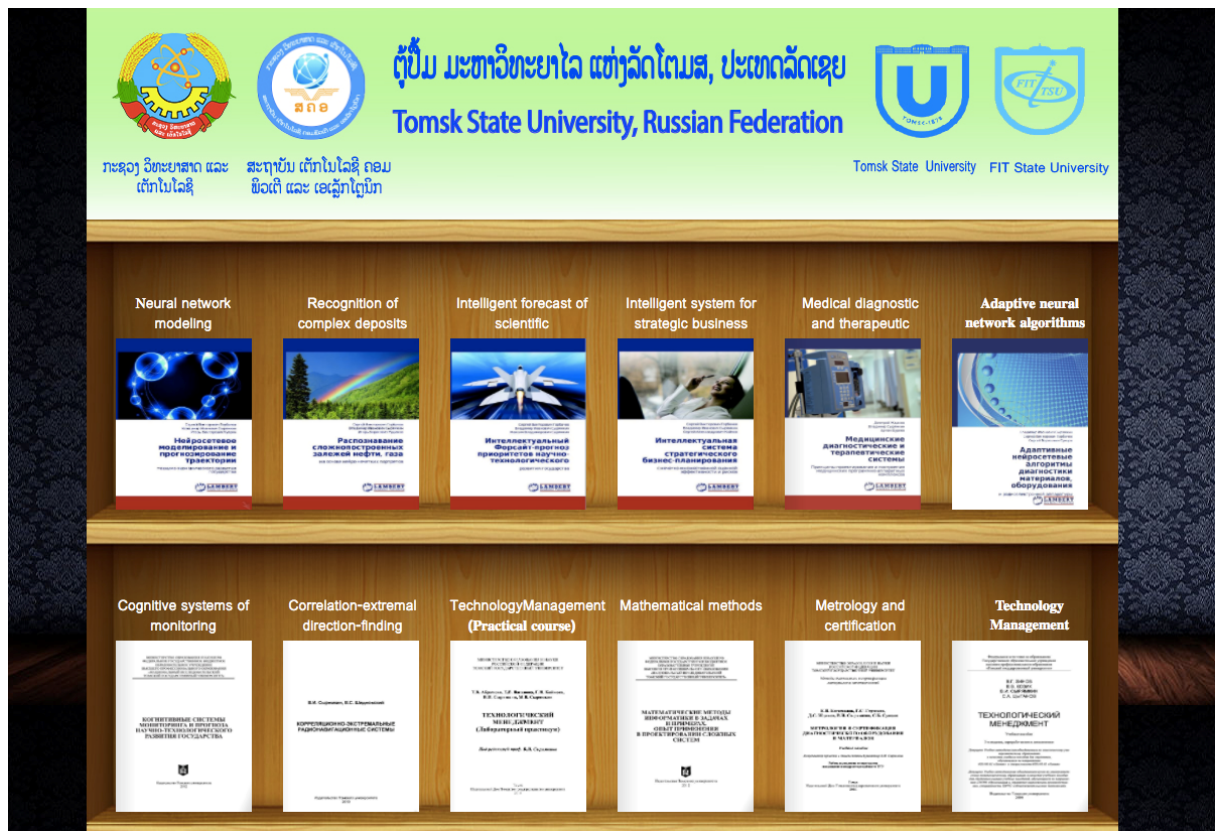

Fig. 3. Interface of E-book collection supported by National Research Tomsk State University [6].

5. E-market. This section provides information on how to use electronic marketplaces, or e-markets, and supplier directories. We focus on e-markets and supplier directories, which have a focus on business-to-business (B2B) or business-togovernment (B2G) cooperation.

- It is open to several buyers and several sellers.

- It is a trading platform, the e-market itself does not sell nor buy goods or services on the platform.

- Supplier directories support companies in establishing new business relationships but no actual trade takes place at these platforms.

- E-markets and supplier directories are also called B2B Internet platforms. Such platforms include all Internet-based technical solutions that aim at facilitating the establishment of new trading relationships between companies or at supporting existing relationships. The focus is put on trade to or between consumers.

\section{Benefits of the Science and Technology Web Portal to Lao PDR}

Benefits of the Science and Technology Web Portal to Lao PDR include the following:

1. Promotion of S\&T policies and indicators in Laos.

2. Improved levels of customer interaction with an increase in customer services.

3. Information storage and viewing.

4. Promoting research opportunities.

5. Digital education (universities, public research institutes, academic societies) and networks (Research Results, Human Resource Development \& Research Cooperation, User Facilities) for students and promising scientists.

6. Promoting S\&T in Laos PDR.

7. Integration of business intelligence (E-Market). 


\section{Problems suppressing further development of the Lao Science and Technology Web Portal}

We have identified some problems, which suppress further development of the Lao Science and Technology Web Portal. They include the following:

1. Proprietary data, access to which is controlled for commercial, national security, or competitive reasons.

2. Lack of comprehensive directory of resources, their content, or access methods.

3. Lack of IT skills on the district, village and provincial level.

4. Lack of requisite software and content in local language.

5. Poor financial support for research in the field of science and technology.

6. Limited capacities to analyze information in S\&T.

7. Poor infrastructure, which leads to slow internet connectivity and its malfunctioning in remote places.

\section{Conclusion}

The Lao Science and technology web Portal intends to foment the transition process from a common education into a digital education. The second main area is e- market aimed to acquaint users with electronic marketplaces and supplier directories, and to introduce ecommerce in each Lao province via business-to-business (B2B) or business-to-government (B2G) cooperation. The third main area of the Lao Science and Technology web portal is making scientific research more accessible to the general audience and particularly to children. In addition, the web portal provides managers with information and support their effective decision-making, provides feedback on daily operations, output, or reports (generated through accumulation of transaction data). The portal will foster reforming and moving forward in developing Lao S\&T system.

\section{Acknowledgements}

The research presented in this paper was supported by the Russian Foundation for Basic Research (grant No 16-29-04388/17).

\section{References}

[1] Science and technology in $\begin{aligned} & \text { Asia. } \\ & \text { https://en.wikipedia.org/wiki/Science_and_technology_in_Asia\#South_Asia }\end{aligned}$
[2] URL:
Introduction of Asia Science and Technology Portal (ASTP). URL:
http://asti.dost.gov.ph/press-room/575-japan-science-and-technology-agency-jst-had-
launched-the-asia-science-and-technology-portal-astp
[3] Background of ASTP. URL: https://www.jst.go.jp/pr/info/info737/index_e.html.
[4] ASEAN Membership URL: http://asean.org/asean/asean-member-states/.
[5] Japan Science and Technology Agency. URL: http://www.jst.go.jp/EN/
[6] Lao Science and Technology Web Portal URL: http://stportal.most.gov.la/

